Noticias

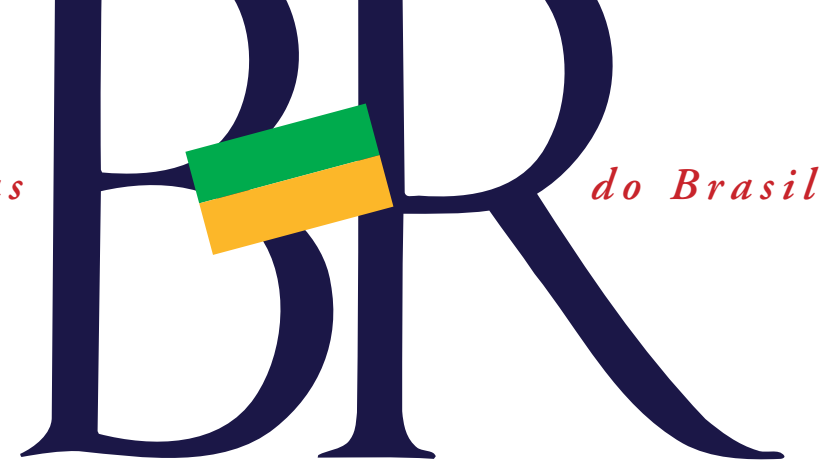

Arqueologia industrial

\title{
Fábricas contam sua história
}

O estudo arqueológico em unidades fabris procura obter informaçōes sobre o processo de produção das mercadorias, a vida dos trabalhadores e a integração que as áreas que estão sendo pesquisadas tiveram e tem com o meio ambiente, entre outros. É esse olhar para o objeto de pesquisa que define um trabalho como sendo de arqueologia industrial. "Muitas vezes se usa o termo arqueologia para se tratar de uma abordagem histórica em relação à edificação, visando ao seu tombamento. Porém, quando se fala em arqueologia industrial, trata-se de uma abordagem focada no equipamento fabrill e seu entorno, enxergando os elementos a partir da arqueologia", explica o arqueólogo Paulo Bava de Camargo que, atualmente, ministra a disciplina Arqueologia Industrial no curso de graduação em arqueologia da Universidade Federal de Sergipe.

Para Leandro Duran, arqueólogo da mesma instituição, a ideia de uma arqueologia industrial surge, como disciplina, na Inglaterra, depois da Segunda Guerra Mundial, após a destruição por bombardeios das edificações da época da Revolução Industrial. "A Inglaterra construiu muito de sua identidade por meio

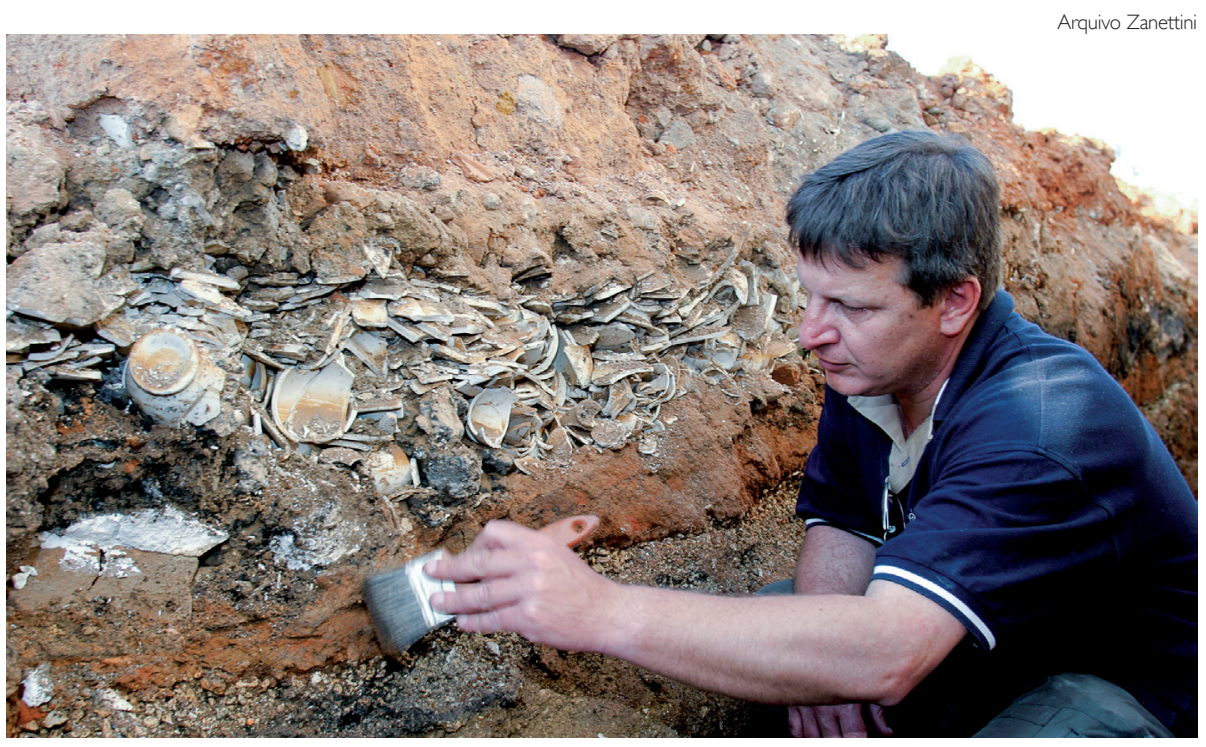

0 arqueólogo Paulo Zanettini trabalha nos escombros da Fábrica de Louças Santa Catharina

dessa questão da expansão da indústria. A arqueologia industrial surge dentro desse processo de identidade urbana, enquanto tema de pesquisa e de reflexão", descreve.

No Brasil, a industrialização maciça começa somente a partir de meados do século XX, quando se tem o primeiro grande processo da formação de indústrias de base, explica Duran. A industrialização, sendo um processo ainda recente na história da humanidade, faz com que haja duas vertentes a respeito da arqueologia industrial: a primeira considera que não é possível um olhar industrial para sítios arqueológicos anteriores ao século XVII, quando ocorreu a Revolução Industrial. Além disso, para essa vertente, indústria é um sistema produtivo em larga escala de bens de capital e de bens de consumo duráveis, que não leva em consideração produçôes de alimentos, por exemplo, como a mandioca, a cana-de-açúcar ou o café.

A segunda vertente considera que a perspectiva do olhar industrial precisa ser interpretada a partir das realidades regionais, sendo um conceito maleável. "Assim, processos produtivos da Roma Antiga e, no nosso caso, do período colonial podem ser vistos sob a ótica da arqueologia industrial, como um engenho ou uma olaria", exemplifica o professor. Para ele, os fatores determinantes para se obter o olhar industrial para o sítio arqueológico são a existência de mão de obra especializada, de conjunto de equipamentos produtivos específicos e técnicos e de produção em larga escala. 
Noticias

UMA INDÚSTRIA NO MAR Na praticamente desabitada Ilha do Bom Abrigo, extremo sul do litoral paulista, Duran deparou-se com uma fábrica de azeite de baleia: eram apenas pedaços de paredes e muros que, aos poucos, foram mostrando sinais das atividades que ali ocorreram. A pesquisa no local foi desenvolvida em seu doutorado, "Arqueologia marítima de um bom abrigo", pelo Museu de Arqueologia e Etnologia da Universidade de São Paulo (MAE/USP), concluído em 2008. O local produzia óleo em larga escala usado como combustível para iluminação, da $2^{a}$ metade do século XVIII até a $1^{\text {a }}$ metade do século XIX. "Tratava-se de uma armação baleeira, que éuma indústria especializada, voltada para o mercado, por isso eu classifico esse meu trabalho como de arqueologia industrial. A gente precisa entender essa questão da indústria não apenas nos limites físicos da operacionalização das relaçôes de produção, do trabalho, mas sim num contexto maior, que significa produção, transporte e consumo", destaca.

As intervenções arqueológicas realizadas revelaram o modo de operação dessa estrutura fabril, suas diferentes áreas de trabalho e as funçôes decada uma delas. "Após várias etapas de campo e escavações arqueológicas, consegui elaborar plantas da armação baleeira, pelas quais fica evidente que a localização das diferentes estações de trabalho foi planejada para fun- cionar como uma linha de produção. Talvez, aqui, tenhamos uma evidência da porção genuinamente capitalista daquela sociedade moderna", reflete o arqueólogo.

\section{QUEBRA-CABEÇA COM 30 MIL PEÇAS A} arqueologia usa peças e estruturas edificadas para contar histórias ao invés de ilustrar histórias contadas em documentos escritos. Foi assim com as quase 30 mil peças de louças resgatadas pela pesquisa realizada em 2003 no sítio arqueológico Petybon, no bairro paulistano da Lapa. O local abrigou a Fábrica de Louças Santa Catharina (1913-1939), a primeira manufatura de louças brancas implantada no Brasil. "Durante as escavaçōes foram resgatadas milhares de peças inteiras, ajudando a retraçar aspectos em torno da história da industrialização e consumo", conta o arqueólogo Paulo Zanettini, responsável pela escavação.

A fábrica foi inaugurada em 1913, tornando-se parte das Indiustrias Reunidas Fábricas Matarazzo em 1927 e funcionando até 1937. "O sítio tem extrema relevância não apenas no contexto da arqueologia urbana no Brasil, como também por ser exemplar dos primórdios da industrialização do país e da história da produção da louça nacional", salienta o arqueólogo Rafael de Abreu e Souza, que participou da escavação e desenvolveu seu mestrado nessa fábrica. $\mathrm{Za}$ nettini completa: "em poucos anos, essa indústria passou a empregar milhares de funcionários; no período entre guerras chegou até a exportar a produção para a América do Norte. Isso mostra também uma capacidade não só de copiar, mas também de criar peças, reunindo o saber do imigrante e o modo de decorar a cerâmica com motivos relacionados ao cotidiano brasileiro. É uma propriedade do saber fazer brasileiro que hoje a gente só pode encontrar no registro arqueológico, pois é raríssimo encontrarmos, mesmo na mão de colecionadores, peças dessa fábrica".

Para Rafael, a diversidade de objetos achados na escavação também pôde contar a história da fabricação de louças antes e depois de movimentos higienistas, que se instalaram em São Paulo no final do século XIX e início do século XX. "A utilização de vidrados e esmaltes e a diminuição do uso de peças não esmaltadas corresponderam ao interesse das políticas higienistas em mudar hábitos considerados nocivos. O começo do século passado marca a necessidade cada vez maior de produtos na cor branca", descreve.

As pesquisas sob a ótica da arqueologia industrial não são realizadas apenas na zona urbana. No entanto, os sítios arqueológicos localizados nas cidades são os que desaparecem com maior rapidez, pois são os que mais sofrem com a pressão econômica, devido à dinâmica do capital.

Glória Tega 